\title{
REFLEXIONES EN TORNO A LA DEMOCRACIA Y BIOÉTICA: LOS NUEVOS FUNDAMENTALISMOS DEMOCRÁTICOS Y BIOÉTICOS
}

\author{
REFLECTIONS ON DEMOCRACY AND BIOETHICS: NEW DEMOCRATIC AND \\ BIOETHICAL FUNDAMENTALISM
}

JUAN GUILLERMO ESTAY SEPÚlVEDA

Universidad de Los Lagos Sede Santiago

juanguillermoestay@yahoo.es

MARIO LAGOMARSINO MONTOYA

Universidad de Valparaíso

mario.lagomarsino@gorevalparaiso.gob.cl

CAROLINA CABEZAS CÁCERES

Universidad de Los Lagos Sede Santiago

carolinacabezascaceres@gmail.com

\begin{abstract}
RECIBIDO: 21/07/2016
ACEPTADO: 19/08/2016
\end{abstract}

Resumen: Es indudable e irrefutable que la democracia es el mejor sistema de gobierno que existe en el mundo occidental y que gracias a ella, la libertad de expresión permite incluso cuestionarla y ponerla en la balanza de la justicia. De igual manera, la bioética nacida en el mundo de las ciencias biológicas y de la salud, ha trascendido a las humanidades y la sociedad ha tomado consciencia de que vivimos en un planeta no renovable. Sin embargo, no podemos pasar por alto que tanto la democracia como la bioética no han nacido del populus, sino que de una élite que sueña un mundo mejor de acuerdo a sus sueños y no los de la gran mayoría de las personas comunes y corrientes.

Palabras clave: Democracia, Bioética, Tecnociencia, Fundamentalismo

\begin{abstract}
It is indubitable and irrefutable that democracy is the best government system that exists in the occidental world and that thanks to it, freedom of expression allows to even question it and put it on the justice balance. Similarly, bioethics born in the world of biological and health sciences, has transcended to the humanities and society has become aware that we live in a nonrenewable planet. However, we cannot overlook that both democracy and bioethics are not born from populus, but from an elite who dreams of a better world according to their dreams and not those of the vast majority of ordinary people.
\end{abstract}

Keywords: Democracy, Bioethics, Technoscience, Fundamentalism 


\section{Introducción}

La problemática de la democracia a partir de la Segunda Guerra Mundial, ha sido una de las grandes cuestiones del siglo veinte y de las primeras dos décadas del nuevo milenio. Al parafrasear a Javier Echeverría, tratamos de responder -como lo hizo él con la tecnociencia y su propuesta de una tecno-ética- (Echeverría 2015) a la bioética y su manto esperanzador de la mano de la misma tecnociencia, la que ha ayudado en forma exponencial al conocimiento científico de alta calidad y a la vez, a convertirlo en un conocimiento predador por parte de publicaciones predadoras (Alonso y Echeverría 2014), cuando esta tecnociencia ha sucumbido al poder economicista.

La democracia no ha sido des-velada en el siglo XXI. Hemos planteado en otros artículos, que la creación ateniense y gritada a los cuatro vientos en un discurso fúnebre por un hijo de Atenas para el propio regocijo de su ciudad, ha vivido con el correr de los años en un manto de sacro respeto, olvidando que ella nació desde nuestra mirada al pasado "xenófoba, clasista y misógina" (Estay Sepúlveda y Lagomarsino 2016a, 6) ${ }^{1}$. La democracia ha mutado con el correr del tiempo en su forma de ser vista por quienes quieren de ella una imagen idealista y de ágora, no comprendiendo que desde su génesis ha sido de un solo grupo, estamento, casta o clase político-económica-social. Sin embargo, y sin repetir la tan trillada frase del mejor de los peores males, esta mutación ha sido para bien de la humanidad. La democracia del siglo XXI es un tema "espinoso e irrenunciable" (Gracia Guillén 2001, 347) cuando se pide una mayor participación de la misma por todas y todos los que participan activa o pasivamente de un Estado o Nación, más aún, cuando esta democracia se vuelve deliberativa (Gracia Guillén, 2002). No obstante lo anterior, hay que dejar en

\footnotetext{
${ }^{1}$ De esa manera lo hemos planteado en Estay Sepúlveda, J. G. y Lagomarsino, M. (2016). “'Tiene enemigos la sociedad abierta de hoy? Una mirada desde la obra Karl Popper", Dilemas Contemporáneos, Educación Política y Valores. Año III, Num. 3, 1-43; Estay Sepúlveda, J. G. y Lagomarsino, M. (2016). "La propuesta que tal vez hubiera impulsado Karl Popper ante los enemigos de la sociedad abierta de hoy: para el Siglo XXI, el reformismo", Revista CS, Num. 20 (forthcomming); Estay Sepúlveda, J. G. y Lagomarsino, M. (2016), "Political attitude in Karl Popper's work: the open society in use in current situation", Ponte Journal, Italia (forthcomming); Estay Sepúlveda, J. G. y Lagomarsino, M. (2016). "Migración: Fundamentalismo y Refugio: la migración desde la óptica filosófica-histórica", ponencia presentada en el Octavo Congreso CEISAL Consejo Europeo de Investigaciones Sociales en América Latina. Universidad de Salamanca, España, 28, 29, 30 de junio y 01 de julio y Estay Sepúlveda, J. G. y Lagomarsino, M. (2016), "Cultura y Fundamentalismo: los nuevos retos de la democracia", ponencia presentada en el Seminario Los Estudios culturales y literarios: Aproximaciones críticas a los discursos y expresiones artísticas locales y regionales. Universidad de Los Lagos, Chile, 28 y 29 de julio.
} 
claro que, la democracia debe analizarse conforme a su situación espaciotemporal, como asimismo, la ética y su nueva hija llamada bioética.

\section{Desarrollo}

Hemos tratado a la democracia desde sus aciertos y desaciertos e incluso desde la óptica de la vulneración de sus propios principios por el bien de la humanidad. Entiéndase bien: humanidad de occidente. Es decir, ante el fenómeno del totalitarismo del período de entreguerras o el fundamentalismo actual, la democracia no debe ser tolerante, respetuosa o deliberativa. ¿Espinudo? Sí. Muy espinudo. Ya que esos totalitarismo llegaron al poder de la mano de la población que vieron como sus líderes no daban respuestas a sus problemáticas. Populismos los hemos llamado. Pero no es populismo también la elección de Rooselvet en pleno conflicto bélico, en un sistema de electores que a los ojos de un latinoamericano no tiene nada de democrático. Recordemos que George W. Bush obtuvo más de medio millón de votos menos que $\mathrm{Al}$ Gore y sin embargo, los halcones se instalaron democráticamente en la Casa Blanca. De ahí lo segundo. La caída de regímenes en Oriente Medio dio paso a los grupos fundamentalistas, muchos de ellos, apoyados por un gran número de la población. La democracia de occidente trajo de vuelta el miedo al propio occidente, al querer intervenir formas y razones de vida totalmente ajenas a nuestro pensamiento. Las cruzadas no se han olvidado por parte de los nuevos fieles del santo grial democrático. Las primaveras dieron origen al poco tiempo a tormentosos inviernos que todavía llenan de nubarrones los cielos del norte de África y del Mediterráneo Oriental. Llevar la democracia con el discurso de la libertad y los derechos humanos, como lo hace la nación más poderosa del planeta que ni siquiera ha firmado o ratificado la Convención sobre la imprescriptibilidad de los crímenes de guerra y de los crímenes de lesa humanidad o la Convención sobre los Derechos del Niño, como asimismo, no reconocer la Corte Penal Internacional, hace que su alardeo y cacareo a otras culturas, pueblos o naciones, nos hagan revivir las palabras de Pericles en boca de Tucídides y su Guerra del Peloponeso, donde la lucha no se da por la libertad y la democracia de la Liga, sino que por, los intereses democráticos y libertarios de Atenas y solamente de sus ciudadanos. El neowilsonianismo en pleno apogeo (Chomsky 2002). Con lo anunciado anteriormente ijustificamos las dictaduras que dieron paso al holocausto, los gulag o las represalias a la libertad en Oriente Medio? No. Para nada. Solamente advertimos que la mujer del César no solamente debe serlo, sino que también parecerlo. 
Ante este principio, la democracia también se convierte en un fundamentalismo cruel. El responder con las mismas armas a quienes la atacan no suena muy democrático que digamos, pero bajo la misma premisa de ser una creación de occidente para occidente y de un grupo para ese grupo en nombre del gran grupo, la legitima cien por ciento. Más aún, cuando ocupamos la democracia para justificar intervenciones o decisiones no democráticas, como las de la administración de los halcones estadounidenses en el Oriente Medio o el aceptar un referendo de los británicos que una de sus consignas para abandonar el bloque europeo fue la migración, el desempleo y la criminalidad que según ellos, comenzaban a ocupar sus calles.

En parte compartimos las ideas de Sen, en cuanto a que esta creación de occidente también se encuentra en otras culturas no occidentales (Sen 2006). Sin embargo creemos, que esa otra "democracia" de África, China o el Oriente Medio es totalmente distinta a la occidental y que no tiene nada que ver en su génesis a la de Occidente. El levantar voces de participación o deliberación, debieran entregarse por ejemplo, y ya lo planteamos, a que se elimine el sistema de electores para las elecciones presidenciales en Estados Unidos por ser poca democráticas y no aceptar la voluntad de la mayoría. La respuesta desde el país del norte no se dejaría esperar y argumentarían que su sistema se basa en la costumbre y la aceptación de todos los ciudadanos. Respetamos esas formas de ver, sentir y obrar por la vida, pero también exigimos respeto por las otras formas de democracia existente en el globo terráqueo. Qué pensaría Tocqueville hoy si tuviera a la mano ambos sistemas de elecciones: la estadounidense y la latinoamericana. Muy probable que la Democracia es de América... de América Latina.

Entiéndase bien. Somos demócratas a ultranza. Pero demócratas que buscan que se reconozca la democracia por lo que es y desde ahí comenzar a trabajar los nuevos paradigmas que se avecinan, como la deliberación de la cual nos habla Gracia Guillén y volver a rescatar la idea, con mucho más fuerza, de la justicia de John Rawls. Democracia y Justicia, que ya lideraron la batalla de la bioética en los años ochenta del siglo pasado, deben revivirse para incrustarlos en el nuevo paradigma de la deliberación sin caer en un nuevo fundamentalismo.

El absolutismo de las ideas se rindió ante el relativismo y lo único absoluto en este tiempo es lo relativo. Los conceptos se han trastocado y han ido mutando. ¿Y es esto algo nuevo o que destruye la evolución humana? Para nada. La historia está construida en el derribamiento de concepciones pétreas, como la esclavitud democrática de la Atenas de Pericles o el poder de decisión de las mujeres para guiar sus propios destinos, pese a que los hombres todavía luchan por seguir escribiendo la historia del hombre y no de la humanidad. Una mochila 
occidental de más de dos mil años es muy difícil de sacudir, pero al mismo tiempo ¡que son dos mil años de historia de occidente ante los millones de años de evolución humana!

La democracia y con ello, compartimos y hacemos nuestras las palabras de Bobbio, es una constante transformación (Bobbio 1986). Ahora, la gran pregunta es ¿Quién dirige esta transformación? Y si aplicamos las ideas de la neutralidad del liberalismo y su problemática de los valores y su consiguiente interrogante "de quien son los valores" (Sandel 2000, 26) a la democracia, tendríamos que llegar al mismo cuestionamiento: ¿De quién son los valores democráticos que pretendemos imponer? y ¿Quienes dirigen las transformaciones democráticas que se pretender conducir? Volvemos nuevamente a la conclusión de la democracia como creación elitista y fiel a su esencia, más aún en América Latina, donde se ha instalado una casta profesional que cuida y valora la democracia conforme a sus propios intereses, los cuales se han institucionalizado (Avritzer 2002). Pero ¿podemos ser tajantes en ello?: No, ya que esta profesionalización democrática la vemos también en otras latitudes occidentales, por lo que la casta democrática se cuida de preservar sus propias conquistas. La realeza ha vuelto en gloria y majestad y su entrega del trono a sus sucesores se hace por la vía democrática del voto o el discurso de la salvación de la patria de las garras del imperialismo, que si bien muchas veces resulta cierto y para ello está la historia que lo corrobora, también es usada como excusa para entronizar sistemas de gobiernos. El caciquismo y caudillismo de la América novel -antes y después a la emancipación- no ha abandona el territorio. El ejemplo de Tijuana y la Baja California y el poder de las elites (Ruiz 2008), es fácilmente replicado en el centro de México como en Santiago de Chile o Brasilia. Nada ha cambiado bajo el sol. Y esta elite tiene las herramientas en la actualidad para hacerlo, ya que la tan utópica masificación de las ideas y con ello, la democratización de las decisiones a partir del surgimiento de las tecnologías de la información y comunicación. Gran falacia decimos nosotros. La tecno-política, no es más que un brazo armado más de las mismas élites que controlan el poder para ir captando mayores adeptos. Panem e circenses cibernético. El que "el uso intensivo y extensivo de Internet implica nuevos reportorios de participación" (Sanpedro, Sánchez y Poetti 2013, 108) no es tan así como se describe. La pregunta, la gran pregunta es, ¿Qué tipo de participación? La consciente, la del posteo, la del like o la del meme. En esta materia, la discusión académica se encuentra en la mesa, con investigadores a favor, como Gilder y en contra, como Hauben y Hauben. Lo percibido por Schumpeter en la sociedad estadounidense a nuestro entender no ha cambiado nada, el veía al demos como "un actor más bien pasivo, guiado por instintos gregarios, sin una clara identidad, que reacciona a 
los estímulos de la propaganda política. Schumpeter descubre, debajo de la palabrería democrática, un régimen oligárquico electoral, donde la participación ciudadana se cristaliza en el acto de votar" (Vidal de la Rosa 2010, 180). Opinamos en forma idéntica. Nada ha cambiado de la visión del austriaco economista al día de hoy. O quizás sí. Hoy, en algunos Estados, hay voto electrónico y más masivo en conocimiento de los candidatos y sus ideas: Existe internet.

Quizás en este momento, se nos acuse de ser discípulos de Feyerabend. Es verdad que la ironía es parte de la gran mayoría de nuestras investigaciones. La diferencia se encuentra en que la ironía si no se encuentra acompañada del argumento sólido y comprobable -en nuestro haber, de la historia y la filosofía-, pierde su esencia. Así como él es un crítico de la ciencia y sus argumentos, nosotros somos críticos de la democracia y los demócratas. Ser demócrata no es quedar bien con todo el mundo. Ser demócrata significa ser crítico con la propia democracia y sus contradicciones. Una verdadera democracia acepta ello, acepta todos los puntos de vistas, sean del científico o del hombre de la calle (Feyerabend 1998).

En cuanto a la bioética, la vemos como una nueva panacea en idéntica sintonía que la tecnociencia. Pretende ser el ideal de la ética. Ideales que han sacudido al mundo desde que Platón se sentó a escribir sus Diálogos. El aristócrata ateniense no es para nada un demócrata sino más bien, un soñador de los gobiernos de los mejores, que para él, no es más ni menos que el gobierno de los reyes-filósofos. Este ideal ha llevado a que la democracia y la bioética pretendan desarrolla leyes naturales, una especia de ingeniería social utópica (Atlántida en todo su esplendor). Por algo Popper coloca a Platón junto a Hegel y Marx como los constructores de grandes fracasos universales y padres de los totalitarismos.

La bioética a nuestro entender -y abiertos a las críticas para perfeccionar, profundizar o corregir nuestro pensamiento-, es otro nuevo fundamentalismo de la modernidad del siglo XXI para justificar la democracia de las élites.

La bioética podrá decir que para su desarrollo y su actuar es "menester excluir los fundamentalismos evitando posiciones extremas, como la cientificista o el moralismo o absolutización de la ética, y valorar actitudes como el respeto al otro, la tolerancia, la fidelidad a los propios valores, la escucha atenta, la actitud interna de humildad, el reconocimiento de que nadie puede adjudicarse el derecho de monopolizar la verdad; esto implica hacer un esfuerzo para ser receptivo, aceptando la posibilidad de cuestionar las propias convicciones desde otras posiciones, y apreciar el enriquecimiento que aporta la competencia profesional interdisciplinaria y la autenticidad en los acuerdos" (Rodríguez 2010, 
7). En las palabras recogidas de la bioética queda claro que no existe un discurso bioético propiamente tal, sino que uno religioso-filosófico y por lo tanto ideológico. Y cuando existe un discurso ideológico -como todo discurso-, existe una elite que lo crea.

He ahí, y aplicaremos un refrán chileno, se encuentra la madre del cordero, es decir, la respuesta a las interrogantes o cuestionamientos a la bioética que hacemos y que la asimilamos al nacimiento de un nuevo fundamentalismo. Todo lo que diga la bioética es verdad. No se cuestiona. Esto para los iluminados demócratas es miel sobre hojuelas.

Ya lo había advertido Gustavo Figueroa en la Revista Chilena de NeuroPsiquiatría del año 2003. Reconoce a la bioética como la gran revolución copernicana en la medicina. Pero a la vez, advierte su universalización, donde sus preceptos se conviertan en verdaderos dogmas: incondicionales, generalizados y vinculantes. (Figueroa 2003).

\section{Conclusiones}

La bioética ha dado un salto gigante desde la medicina y la biología a todo el espectro del conocimiento humano. Todo hoy es bioético. Y no está mal que se cuestionen las verdades irrefutables de los sabios academicistas. Gracias a la bioética el mundo ha tomado consciencia de que existen ríos a los cuales no hay que contaminar, animales que no deben extinguirse o seres humanos de pueblos originarios que deben ser juzgados por sus costumbres ancestrales y no por normas y leyes occidentales, aunque ellos, ya estén occidentalizados. La bioética abrió el espacio al reconocimiento pluricultural y la diversidad.

El problema es otro. En que esta moda bioética se convierta en fundamentalismo. Lo hemos repetido varias veces. Quienes van a establecer los cánones bióticos. Quienes escribirán las planchas de la nueva ley bioética. Quienes dirán lo que es bioético bueno y bioético malo. Predicciones como que "el futuro de la bioética no es otro que el presente del hombre y su estar en el mundo. No es otro que el de la experiencia de ser en todas sus facetas, todos sus dilemas y todos sus enigmas" (Seguró 2015, 224), nos parecen más que suficientes para que Popper se revuelque en su tumba.

Para concluir, solo una muestra. Que dice la bioética ante la discusión de la ley de aborto en Chile. Algunos dirán apoyándose en la bioética, que la vida es sagrada y otros, apoyándose también en la bioética, que el respeto a la libre determinación y deliberación de la mujer es sagrada. Y he aquí el problema que ya vemos en la actualidad. Médicos amparándose en la libertad de objeción de 
conciencia y otros médicos amparándose en la deliberación del paciente-sujeto. Mientras tantos, quienes realmente deben deliberar por su cuerpo no tienen voz ni voto, ya que los iluminados de siempre, amparándose en novedosas modas de academicistas, darán su veredicto conforme a $s u$ pensamiento y el que creen que es bueno para la población. Total, fue todo en democracia y refrendado bioéticamente.

\section{Referencias Bibliográficas}

Alonso, A. y Echeverría, J. (2014). "Lucha de Paradigmas: Leyes. Ciencia y Activismo en el mundo Open”, Argumentos de razón técnica, 17, pp. 21-38.

Avritzer, L. (2002). Democracy and the Public Space in Latin America, Estados Unidos, Princeton University Press.

Bobbio, N. (1986). El futuro de la democracia, Ciudad de México, Fondo de Cultura Económica.

Chomsky, N. (2002). Una nueva generación dicta las reglas, Barcelona, Editorial Crítica.

Echeverría, J. (2015). "Ética y racionalidad tecnológica a partir de Ramón Queraltó", Argumentos de razón técnica, 18, pp. 15-37.

Estay Sepúlveda, J. G. y Lagomarsino, M. (2016a). "Reflexiones en torno a la democracia, el fundamentalismo y la tecnociencia. Popper revolcándose en su tumba ante el nuevo historicismo de la "i”, Dilemas Contemporáneos, Educación Política y Valores, Año IV, Num. 1, 1-10.

Estay Sepúlveda, J. G. y Lagomarsino, M. (2016b). "Migración: Fundamentalismo y Refugio: la migración desde la óptica filosófica-histórica". Ponencia presentada en el Octavo Congreso CEISAL Consejo Europeo de Investigaciones Sociales en América Latina. Universidad de Salamanca, España, 28, 29, 30 de junio y 01 de julio.

Estay Sepúlveda, J. G. y Lagomarsino, M. (2016c). "¿Tiene enemigos la sociedad abierta de hoy? Una mirada desde la obra Karl Popper", Dilemas Contemporáneos, Educación Política y Valores. Año III, Num. 3, 1-43.

Estay Sepúlveda, J. G. y Lagomarsino, M. (2016d). "La propuesta que tal vez hubiera impulsado Karl Popper ante los enemigos de la sociedad abierta de hoy: para el Siglo XXI, el reformismo". Revista CS, Num. 20 Septiembre-Diciembre 2016 (forthcomming). Universidad Icesi, Cali, Colombia: Facultad de Derecho y Ciencias Sociales.

Estay Sepúlveda, J. G. y Lagomarsino, M. (2016e). Cultura y Fundamentalismo: los nuevos retos de la democracia. Ponencia presentada en el Seminario Los Estudios culturales y literarios: Aproximaciones críticas a los discursos y 
expresiones artísticas locales y regionales. Universidad de Los Lagos, Chile, 28 y 29 de julio.

Estay Sepúlveda, J. G. y Lagomarsino, M. (2016f). Political attitude in Karl Popper's work: the open society in use in current situation", Ponte Journal (forthcoming).

Feyerabend, P. (1998). La ciencia en una sociedad libre, México D. F., Siglo XXI Editores.

Figueroa, G. (2003). “¿Un intruso junto al lecho del enfermo? La bioética cumple treinta años”, Revista Chilena de Neuro-Psiquiatría, Vol: 41, Num. 2. 8994.

Gilder, G. (2000). Telescom. How infinite bandwidth will revolutionize our world, New York, The Free Press.

Gracia Guillén, D. (2001). "Democracia y bioética", Acta Bioethica, Año VII, Num. 2, 343-354.

Gracia Guillén, D. (2002). "De la bioética clínica a la bioética global: treinta años de evolución", Acta Bioethica, Año VIII, Num. 1, 27-39.

Hauben, M. y Hauben, R. (1997). Netizens: On the History and Impact of Usenet and the Internet, California, IEEE Computer Society Press.

Rawls, J. (1997). Teoría de la justicia, Ciudad de México, Fondo de Cultura Económica.

Rodríguez Yunta, E. (2010). "Religión y Bioética", Acta Bioethica, Vol: 16, Num 1, pp. 7-8.

Ruiz, B. (2008). La democracia de las élites. La lucha por el poder en Tijuana, Tijuana, Librería El Día/Editorial Entre Líneas.

Sandel, M. (2000). El liberalismo y los límites de la justicia, Barcelona, Gedisa. Sampedro Blanco, V.; Sánchez Duarte, J. M. y Poletti, M. (2013). "Ciudadanía y tecnopolítica electoral. Ideales y límites burocráticos a la participación digital", Co-herencia, Vol. 10, Num. 18, pp. 105-136.

Suguró, M. (2015). El "Ethos" de la ciencia y el estatuto de la bioética", Acta Bioethica, Vol: 21, Num. 2, pp.217-225.

Sen, A. (2006). El valor de la democracia, Barcelona, Ediciones de Intervención Cultural/El Viejo Topo.

Vidal de la Rosa, G. (2010). "Teoría Democrática. Joseph Schumpeter y la síntesis moderna”, Nueva Época, Año 23, Num. 62, pp. 177-199. 
